\title{
Research and Study on Credit System of Shanghai E-Commerce Enterprises
}

\author{
HaiLan Pan ${ }^{1, a^{*}}$, WenJing Wei ${ }^{1, b}$ and YuHan Wang ${ }^{1, c}$ \\ ${ }^{1}$ School of Economics and Management, Shanghai Polytechnic University $360 \mathrm{HaO}$, JinHaiLu, \\ PuDong Shanghai 201209 China \\ apanhailan@sspu.edu.cn, bwjwei@sspu.edu.cn, cyhwang@sspu.edu.cn
}

Keywords: Credit system; E-Commerce; Evaluation Index; Data evaluation

\begin{abstract}
In recent years, with the outbreak of such issues as the disclosure of personal information and the unrealistic price cuts of Taobao shops, it is not difficult to see that many problems concerning the credit of electronic commerce have begun to be uncovered continuously, thereby hindering the further development of E-commerce and establishing a complete set of electronic Business credit rating system is the key to solve the credit problem of E-commerce. Based on the causes of credit risk in E-commerce and the existing problems in the system, this paper conducts research and analysis on 9 representative E-commerce enterprises in Shanghai and puts forward credit evaluation indexes so as to improve their standards and promote E-commerce more stable, healthy and rapid development.
\end{abstract}

\section{Introduction}

In recent years, with the rapid development of global e-commerce, governments of all countries attach great importance to the development of e-commerce. Taking e-commerce as a new economic growth point, they are gradually pushing e-commerce to achieve cross-regional and inter-economic development and extending it to globalization. According to the "Research Report on E-commerce Talents in China 2016" issued by China E-Commerce Research Center, under the background of rapid development of the industry, talent, honesty and logistics together have become the three major bottlenecks affecting the development of e-commerce industry. Online fake sales become the online retail electricity supplier's "number one cancer", the direct credit e-commerce business integrity system; information disclosure exposed the business enterprise technology loopholes and internal management issues; and in the new "Consumer Protection Law" proposed Of online shopping, "no reason to return within seven days", the actual operation has also been repeatedly executed are not in place; after-sales service attitude also exposed the shortcomings of e-commerce customer service ${ }^{[1-2]}$. All of these factors have affected the development of e-commerce in our country to a certain extent, and we urgently need the good faith management of online retailers and do a good job in all aspects of service.

\section{The Background and Purpose of Research}

The survey was conducted by Shanghai Electronic Commerce Association and Shanghai Polytechnic University. The whole project planning started from the perspective of "establishing and perfecting credit rewards and punishments and risk prevention mechanisms," and selected "e-commerce" as the specific industry and The research on the establishment and perfection of credit rewards and punishments and risk prevention mechanisms is the key issue for the country, Shanghai local and e-commerce industry, which will have a greater impact on the improvement of economy and market environment.

Based on the current credit and normative operation level of Shanghai e-commerce enterprises, this research will include the field investigation of representative e-commerce enterprises, the investigation of operation information of some enterprises, the search of relevant data of the network and government-related policies Research, specifically for the development of Shanghai's e-commerce 
industry research, in 2015 e-commerce enterprises lack of credit main types of research, e-commerce business normative research, e-commerce business credit research and so on.

Through this investigation and interview, I hope that after a large amount of data integration, the interim draft of "Reference Index for E-commerce Credit Evaluation" will be conducted in consultation with enterprises so as to modify the description of indicators and the weight adjustment of indicators at all levels so as to provide follow-up formal indicators and assessment Model provides a reliable basis.

\section{The Basic Situation of Research}

Enterprise Research Situation. The research firm selected a representative e-commerce enterprise in Shanghai and covered a wide range of industries including home appliances, telecommunications, tourism, logistics, home improvement, agricultural products, telecommunications, machinery and new media, Limited to include all categories of Shanghai engaged in e-commerce activities of enterprises, the choice of enterprises in different fields will provide follow-up indicators and models to provide reliable analysis data.

Research Content and Methods. The main contents of the field research of this enterprise come from the "Temporary Indicators of E-commerce Credit Evaluation Reference" planned by the project team as shown in Table 1 below. Conducting research on the first and second level headings of the indicators, investigating the related credit rating measures of the enterprises from five aspects and helping to adjust the indicators and establishing the follow-up model.

Table 1 E-commerce credit rating reference index (temporary)

\begin{tabular}{|l|l|l|}
\hline No. & main indicators & Secondary indicators \\
\hline 1 & $\begin{array}{l}\text { The basic situation of } \\
\text { enterprises }\end{array}$ & $\begin{array}{l}\text { Declaration of information, the latest business inspection, } \\
\text { website filing time, the construction of enterprise systems, etc. }\end{array}$ \\
\hline 2 & Certification & $\begin{array}{l}\text { International standard certification, international honor, } \\
\text { domestic certification (General), etc. }\end{array}$ \\
\hline 3 & Trading environment & $\begin{array}{l}\text { Product quality assurance system, cumulative transaction size, } \\
\text { activity, effective transaction rate, e-commerce / customer size, } \\
\text { market share, asset-liability ratio, return on net assets, etc. }\end{array}$ \\
\hline 4 & Customer Reviews & $\begin{array}{l}\text { Customer evaluation, media and official negative information, } \\
\text { customer complaints, evaluation of third party organizations, } \\
\text { etc. }\end{array}$ \\
\hline 5 & $\begin{array}{l}\text { Payment } \\
\text { environment }\end{array}$ & $\begin{array}{l}\text { Account security, timely refund, delivery, timeliness of delivery, } \\
\text { third-party logistics and on-time delivery rates, third-party } \\
\text { payment management success rate, etc. }\end{array}$ \\
\hline
\end{tabular}

Through the conclusion of the previous research, we initially consider the use of a comprehensive evaluation method. The comprehensive evaluation model is as follows Eq. 1:

$$
\mathrm{Y}=(1-f) \quad(\mathrm{W})+f(\mathrm{X})
$$

Where $\mathrm{Y}$ is defined as e-commerce business credit comprehensive evaluation, $\mathrm{W}$ is defined as e-commerce business operating standard evaluation, $\mathrm{X}$ is defined as credit factor evaluation, $f$ is defined as weighting coefficient., which is more suitable for e-commerce business credit rating. Eq. 1 can better adjust the assessment methods and models.

\section{Feedback Analysis of Enterprise Problem}

Tianyi E-commerce Co., Ltd. Shanghai Branch. The company researchers surveyed pointed out that the e-commerce business credit evaluation of the enterprise itself is very important indicators of common information, especially its financial indicators and profit models, etc., can raise a certain score, preferably accounting for more than $60 \%$. E-commerce features indicators: transaction, payment, 
logistics, value-added services, financial transactions more emphasis on four indicators, which buyers and sellers pay more attention to the information in the seller, because the corporate credit more focused on the assessment of repayment ability.

On the choice of indicators, the other party indicated that it wished to minimize the qualitative indicators while reducing the weight of data that is important but difficult to obtain or difficult to reconcile (such as financial data and transaction data). In addition, it is suggested to remove some of the manual evaluation indicators. The other party also proposed that the model must be set up after the model is adjusted, reflow and noise processing.

Shanghai Suning E-commerce Co., Ltd.The company's research staff introduced us to their own credit rating initiatives and provided detailed responses and clarifications to our research questions. The other party pointed out that the design of the indicator system should consider the service target, the main target of the service should be the consumer, and may also include the government (tax, subsidy) and the supplier. There should be different indicators. As far as consumers are concerned, the focus of consumers in the current market centers on the following contents: information security, online shopping environment, price management, product quality, logistics indicators and dispute resolution mechanisms, etc. In addition, there should be a third-party platform for consumption Tucao complaint. And if from the government point of view the relationship between tax payment, arrears and other content to start.

The other party also pointed out that the second key to indicator design is the availability of data. As for the internal data of enterprises, such as finance, trading, logistics and external access are difficult to obtain, what is the follow-up work of our party? The other on the financial, corporate data and other information needs as a part of e-commerce business credit indicators to be discussed? If you consider the overall competitiveness of enterprises without objection, otherwise not recommended.

SF Express Group (Shanghai) Express Co., Ltd.In addition to answering the survey questions, the most important thing for the company to accept researchers is to point out that enterprises should account for $50 \%$ of the general indicators and $25 \%$ for the management and evaluation of the businesses.

Shanghai Jingyu Culture Communication Co., Ltd.The company accepted the researchers pointed out that credit indicators depends on their application scenarios, different scenarios should be different indicators, including the company's general indicators, Internet and professional indicators of the area, of which the common indicator should account for at least $40 \%$ of the weight.

Researchers also pointed out that the Internet features mainly emphasize the reliability of the system, the buyer and the seller guarantee and information security, financial services can be ignored and so on.

Shanghai Rural Credit E-commerce Co., Ltd.The company accepted the researchers pointed out that the financial indicators can be removed, this irrelevant credit, only an individual means of profit only one. Another indicator difficult to obtain data need careful consideration, whether to reduce the weight? Hope this indicator can promote the government to introduce the corresponding policies, especially for food enterprises is very important.

Shanghai Oriental E-commerce co., LTD. The company accepted the researchers pointed out that the indicators should be divided into qualitative indicators and quantitative indicators, the other considered the important indicators are: supplier management evaluation and control, online product quality control, service quality evaluation and corporate credit system. The company proposed to strengthen legislative supervision and industry standard construction, and enhance awareness of TV shopping practitioners conscious of social responsibility, so as to enhance the credit rating of the entire industry.

Shanghai Hong-Yang Electronic Commerce Co., Ltd.The company accepted the researchers pointed out that staff qualifications do not reflect the corporate credit, not recommended to use, transaction management and trading agreements is very important. In addition, they are more interested in the indicators of the buyer and seller, and think this is the most important indicator of the electricity supplier. For financial services, the company considers this to reflect the financial viability of the business and from another perspective on the creditworthiness of the business. 
Best Tong Information Services Co., Ltd.The company accepted the researchers conducted an analysis of the first level indicators of this study one by one for the basic information section, the company that in addition to the general business information, customer and merchant evaluation, the rules of the transaction, these information is easy to obtain, but also complete, But most of the enterprises will make provisions of credit rules of good faith for supply sources and customers according to their own needs. Do these need to be considered? For network technology security, it can be used as a concept of variables and weighted and quantified as a standard. Because of the need to constantly update to ensure their safety, improve the score is high, without a low score; for the quality of human resources, they do not think they can only qualifications as the quality of personnel evaluation criteria.

The other company that the comprehensive competitiveness of enterprises and the relevance of credit is not high, the size and length of the business cycle should be adjusted accordingly the weight of the relative number of concepts and consider the strength of the parent company behind; for the sale Both parties should issue a unified e-commerce industry standard. For the transaction information, it is suggested to add three indicators of "product prosecution system", meanwhile, it is suggested to set up a platform customer service evaluation index and separately consider the platform customer service and the business customer service situation. Another effective transaction rate should increase the logistics indicators, taking into account the delivery, delivery time within the commitment rate. Non-third-party warehouse delivery and third-party warehouse delivery evaluation criteria should be different.

Shanghai EM chain mechanical and electrical equipment Co., Ltd.The company accepted the survey staff because there is no specific contact with this business, the information mentioned on the research is relatively weak, the other party believes that access to corporate information can be directly used by banks to issue a letter of credit, the financial business of mechanical e-commerce is very Important, but also pointed out that staff education and credit has little to do directly.

The above feedback from different types of enterprises will serve as an important basis for the subsequent evaluation of credit rating.

\section{E-commerce credit rating common indicators}

The Issue of Credit Building about E-commerce companies. It is imminent to establish a scientific and reasonable e-commerce credit evaluation model, which will play an important role in the healthy development of e-commerce industry in our country. However, many problems need to be solved, which can be roughly summarized from the aspects of enterprise compliance and enterprise credit evaluation Put forward some urgent problems to be solved.

Corporate compliance includes infrastructure, transaction management, logistics services, financial services and e-commerce systems, and corporate credit evaluation issues include basic management, comprehensive competitiveness, transaction information, financial information, supply Business information and details, we do not elaborate here.

E-commerce credit rating common indicators. Through the investigation of nine enterprises and the search of a large amount of network data, some suggestions and opinions on the original index contents are put forward. First of all, we must make sure the trustworthy object of the e-commerce platform should be platform buyers and sellers, especially buyers. Second, we must subdivide the index system, divided into general indicators and e-commerce business characteristics indicators. Finally, consider the availability of data, such as finance, trading, logistics, the external hard to obtain, for these important but difficult to obtain or difficult to check the data, it is recommended to reduce the weight ${ }^{[3]}$.

Finally, the following seven major first-level indicators and related second-level indicators are identified:

- information disclosure (including corporate identity, annual inspection information, financial information, etc.);

- management practices (including system security, network security, etc.);

- Competitiveness analysis (including human resources, R \& D investment, operation and management status, competitive position, etc.); 
- Seller information (including transaction size, quality of service, effective transactions, product quality, means of payment, transaction information, etc.);

- Buyer information (including identification, ability to pay, historical data, performance, etc.);

- logistics services (including distribution services, privacy protection, logistics systems, etc.);

- Value-added services (including account management, financial support, financial management, value-added services, etc.).

The above seven first-level indicators will be an important basis for the follow-up evaluation model. Whether these indicators can establish a reasonable credit evaluation model and whether they can recognize the activities of enterprises requires the follow-up work to be further carried out ${ }^{[4]}$.

\section{Summary}

Credit evaluation of enterprises in e-commerce environment and the prediction of their future behavior with the past performance of the enterprises help transaction parties to evade credit risk and establish mutual trust so as to create a sound credit environment.

Through the integration and analysis of various parts of the data, the survey initially adjusted seven first-level indicators and over 26 second-level indicators and basically covered the items related to credit evaluation related to the operation and operation of e-commerce enterprises. Hope that these indicators through the project in the late quantitative analysis of the final access to corporate credit system standards. Through this survey, project team members agreed that only the establishment of e-commerce credit rating system is only the first step, but also need to establish the appropriate network system for quantitative credit rating of enterprises, of course, the government also issued for different sectors of the corresponding industry standards And service standards, which are conducive to the implementation of Shanghai's e-commerce credit system and healthy development.

\section{Acknowledgements}

This paper is sponsored by Management Science and Engineering project of Shanghai Polytechnic University (No. XXKPY1606).

\section{References}

[1] De Nicola A, Missikoff M, Smith F. Towards a method for business process and informal business rules compliance. Journal of Software: Evolution and Process, 2012, 24(3): 341-360.

[2] Jehn K A, Rispens S, Thatcher S. M. The effects of conflict asymmetry on work group and individual outcomes. Academy of Management Journal, 2010, 53(3): 596-616.

[3] Liu H, Abraham A, Hassanien A E. Scheduling jobs on computational grids using a fuzzy particle swarm optimization algorithm . Future Generation Computer Systems, 2010, 26(8): 1336-1343.

[4] Ming G, Li H. An Improved Algorithm Based on Max-Min for Cloud Task Scheduling. Springer Berlin Heidelberg, 2012: 217-223. 